Available online at GSC Online Press Directory

GSC Biological and Pharmaceutical Sciences

e-ISSN: 2581-3250, CODEN (USA): GBPSC2

Journal homepage: https://www.gsconlinepress.com/journals/gscbps

(RESEARCH ARTICLE)

\title{
Classification of cucumber germplasm based on agronomic traits under natural climatic conditions
}

Shehzaib Asad 1, Sadique Muhammad Adnan 2, ${ }^{*}$, Farooq Muhammad Umer 2, Shaker Muhammad Afsar Ali ${ }^{3}$, Aleem Ujiara Kainat ${ }^{4}$ and Sana Rubab ${ }^{3}$

${ }^{1}$ Institue of Horticulture Sciences, University of Agriculture, Faisalabad.

${ }^{2}$ Department of Horticulture, Bahaudin Zakariya University, Multan.

${ }^{3}$ Department of Entomology, Bahaudin Zakariya University, Multan.

${ }^{4}$ Department of Environmental Science, COMSATS University Islamabad, Vehari Campus.

Publication history: Received on 06 February 2020; revised on 14 February 2020; accepted on 19 February 2020

Article DOI: https://doi.org/10.30574/gscbps.2020.10.2.0034

\begin{abstract}
Vegetables have been known from ancient times as fresh and edible parts of herbaceous plants. They play vital role in maintenance of health and help in prevention from a number of diseases. Vegetables have been main source of carbohydrates, vitamin and mineral. Vegetables can be available in different edible forms such as roots, stems, leaves, fruits and seeds. Each edible group have its own contribution. Cucumber is cultivated all around the world and held an important position in cucurbitaceous crops. Seeds of cucumber have cooling, tonic, diuretic and anthelmintic effect. There were total 12 different varieties and central devoutness of the study was to compare all these varieties and to know about the best variety among all. After comparing means from data it was conducted that in terms of days of germination, the fastest germination rate was observed that three varieties C-571, Cucumber Vega and Desi cucumber respectively followed by $\mathrm{C}-3429$ and remaining varieties showed almost same trend, but the variety which took highest number of days to germinate was C-574. All the varieties showed almost similar trend in length of stem and days of flowering. C-3479 possessed highest number of fruits and Sialkot local had lowest number of fruits. Three varieties C-571, 574 and C-3429 exhibited highest yield. The biggest size of leaf was variety WANDRI-700. This study revealed the germination rates and the fastest germination rate was observed that three varieties C-571, Cucumber Vega and Desi cucumber. In terms of Numb of leaves C-3479, C-571 and Sialkot local beard highest number of leaves.
\end{abstract}

Keywords: Germination; Varieties; Cucumber; Vegetable

\section{Introduction}

Vegetables have been known from ancient times as fresh and edible parts of herbaceous plants. They play vital role in maintenance of health and help in prevention from a number of diseases. Vegetables have been main source of carbohydrates, vitamin and mineral. Vegetables can be available in different edible forms such as roots, stems, leaves, fruits and seeds. Each edible group have its own contribution [1]. Cucumber is a significant participant of family Cucurbitaceae.118 genera and 825 species have been included in this family. Tropical plus sub-tropical region of the biosphere has been greatly known for distribution of cucurbit family members [2]. Cucumber is in cultivation for last over 3000 years and is thought to be originated in India. It further spread East ward to China plus West ward to Asia Slight, North Africa plus Southern Europe Regarding the ancestral form, Sir Joseph Hooker concluded that Indian wild cucumber (Cucumis sativus var. Hardwicke Kitamura.) which is originate growing wild in the slopes of Himalaya, as either feral or progenitor of present day cucumber [3].

\footnotetext{
${ }^{*}$ Corresponding author

E-mail address: Adnansadique094@gmail.com
} 
In climate-sensitive areas, cucumbers can swell as the main fruit in the spring also as an extra fruit in the summer. In his production area, there must be well drained soil and covered plastic packaging. Weed growth should be avoided. If necessary, water should be applied by drip irrigation. Destructive harvesting again and again, because the shape of the transformed cucumber is based on concentrated fruit. Its plants are a trailing (climbing), usually monoecious, with vines surrounded by vines two to ten feet long each year. Undetermined growth in cucumbers and may vary in sexual performance. It is grown with its edible green fruit. Fruit can be deposited at each node and more than one type of fruit can be produced at the node. It is usually best to use only a few fruits in the fruit to alleviate the taste of these grapes. However, strong plants can sometimes mature multiple cucumbers on one knot. Miniature shapes and Beit alpha support many fruits per node. The least deformed fruit should be replaced immediately. The maximum growth of fruit occurs between the sixth and fourth days after flowering (flowering). The maximum fruit size occurred on day 14, followed by an increase in diameter [4]. Cucurbit family mostly consist of annual herbs, however some are semi herbs which consists of climbing growth habit and some cucumber and melons have habit of bush. root system is woody and very long along with shallow and tuber habits. Stems are sulcate, angled along with sympodial branch pattern, whereas nodes may be geniculate or non-geniculate. Simple and petiole types of leaves, length of petioles differ. Blade of leaf may be kidney shape, circular or ovate. Cucumber consist of unisexual and hermaphrodite flowers. Cucumbers are known as monoecious flowers because they produce male also female flowers distinctly on same plant [5].

Cucumbers have many type of sexual expression ways. Male flower consists of solitary flowers sometimes it is multi flowered and with branching habit. Female flowers are also solitary along with habits of rarely compound shape modified flowers. There pedicle is sulcate with pubescent. Their fruit size varies from round lobately elongated oval to block shape. Fruit surface may be soft or semi soft to hard with slightly hairy growth on it. Color of fruit varies from green to yellow to pale yellow. Sex expression is totally dependent upon a number of environmental factors such as temperature and plant hormones [6]. Cucumber produces three types of flowers: stamens and pistils are also perfect. It is known that ethylene is used exogenously to promote the production of biculate dies and thereby increase fruit yield $[7,8,9,10]$. Cucumbers have undergone significant changes during their domestication. Many fresh forms have been developed, such as female plants, and shrub species (particular growth of the main trunk and compressed internodes) or leaves without leaves (silk less) varieties are also common Stems [11].

Study was purposed to examine the effect of agro climatic conditions on a number of different varieties to check effect of climate on yield related traits through germplasm collection.

\section{Material and methods}

\subsection{Plant Material}

Seeds of twelve cucumber cultivars were occupied from National Agriculture Research Centre (NARC) Islamabad.

\subsection{Cultivars}

T1, V1: CUCUMBER VEGA, T2, V2: C-3479, T3, V3: PICO-500, T4, V4: KN-84604105, T5, V5: C-3426, T6, V6: C-571, T7, V7: WANDRI-800, T8, V8: C-3426, T9, V9: C-574, T10, V10: SIALKOT LOCAL, T11, V11: C-3429, T12, V12: DESI CUCUMBER.

\subsection{General Layout of Research}

A number of 5 seeds per variety were selected for cultivation in one row with line to line distance of $1.5 \mathrm{ft}$. Sowing was done by hand. At regular intervals of days' random sample from field were collected and bring in the laboratory for analysis purpose. The whole collection and sampling were done up to four months after sowing. The main purpose was to evaluate the best variety with high yielding attributes under agro climatic condition. A number of observations done regarding to this purpose are enlisted below.

\subsection{Day to Germination}

Sum of days was recorded from first ever sowing to germination. Random plant selection was done and mean value of days were noted.

\subsection{Number of Leaves}

A number of 5 plants were selected from every block, total number of leaves were noted. Finally, average was taken. 


\subsection{Length of the Stem (cm)}

Total vine length was recorded by selection of random plants at the end of flowering season and their average was recorded.

\subsection{Days to First Flowering}

Entire number of 10 plants were selected randomly and their first blooming and number of flowering were recorded from their primary nodes.

\subsection{Number of Fruits / Plant}

The whole number of fruits which were picked at every harvest was noted and average value was taken from randomly selected 10 plants.

\subsection{Yield / Plant (kg)}

Total number and marketable fruits weight being harvested from individually block was summarized and recorded as yield / block. From this worth yield / plant was calculated.

\subsection{Statistical Analysis}

The experimented was subjected to randomized complete block design (RCBD). ANOVA and DMR was used for major analysis as well as variations between mean data observed (Steel et al., 1997). By using R studio statistical analysis was done.

\section{Results}

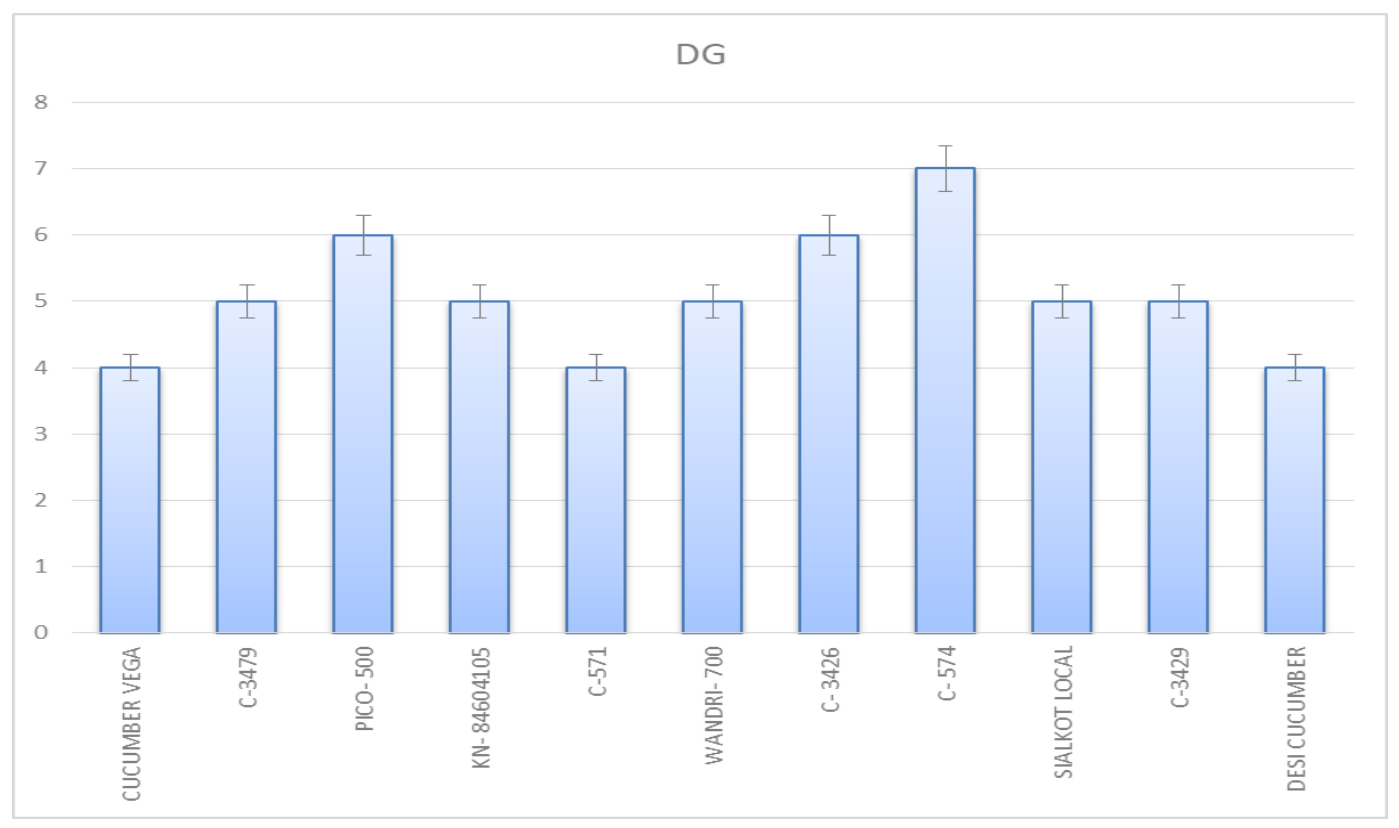

Figure 1 Mean comparison analysis for Days of Germination

Figure 1 shows the mean comparison analysis for Days of Germination. The grouping information figure shows groups of factor level means that are significantly different. This figure is based on the confidence intervals that are displayed in the interval plot. Groups are listed in descending order of their fitted means for the number of treatments. Groups that share a letter, such as treatment T5 and T8, are significantly different; these two treatments' products allowed the most observation to survive. Conversely, groups that do not share a letter have significantly different means. 


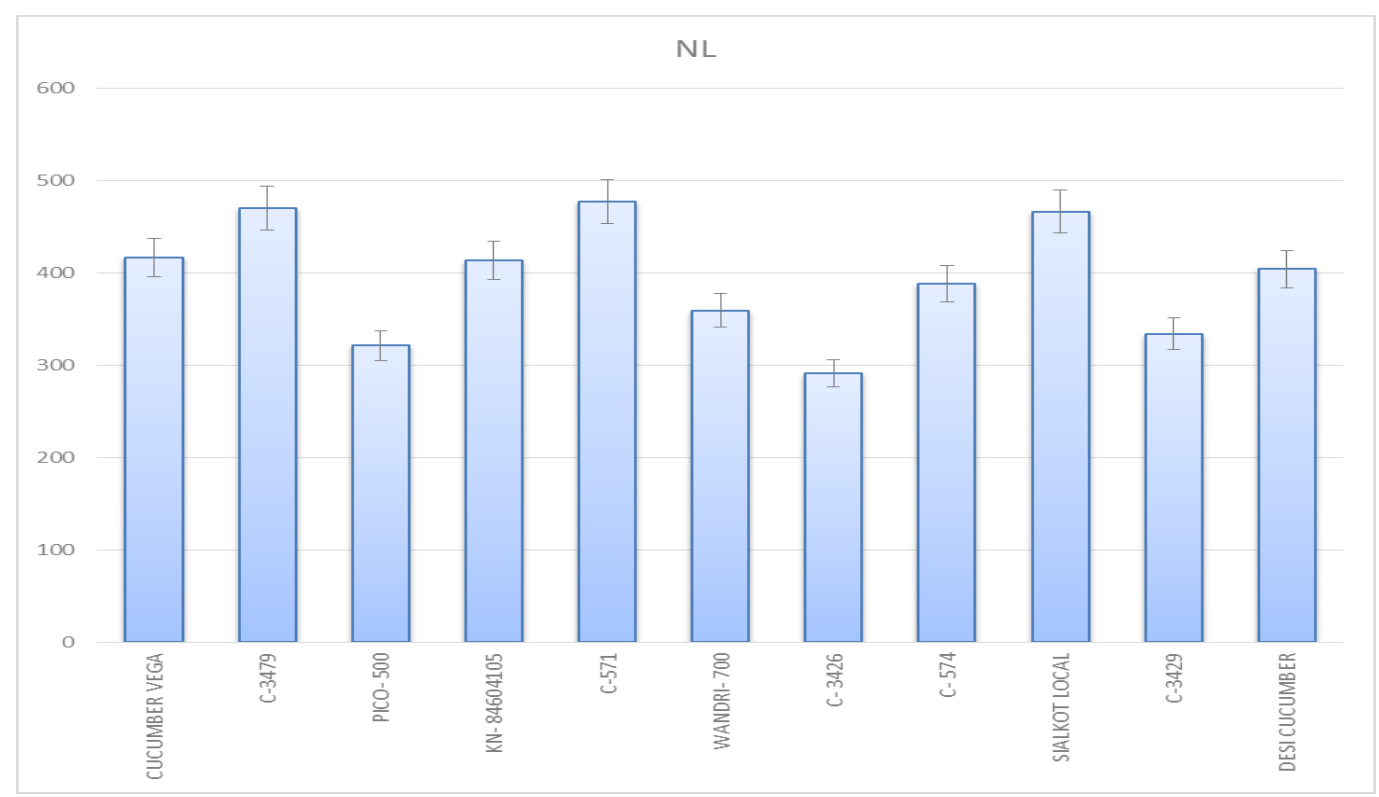

Figure 2 Mean comparison analysis for Number of Leaves.

Figure 2 shows that the mean comparison analysis for Number of Leaves. The grouping information graph shows groups of factor level means that are significantly different. This graph is based on the confidence intervals that are displayed in the interval plot. Groups are listed in descending order of their fitted means for the number of treatments. Groups that share a letter, such as treatment T1, 5 and T9, are significantly different; these two treatments' products allowed the most observation to survive. Conversely, groups that do not share a letter have significantly different means.

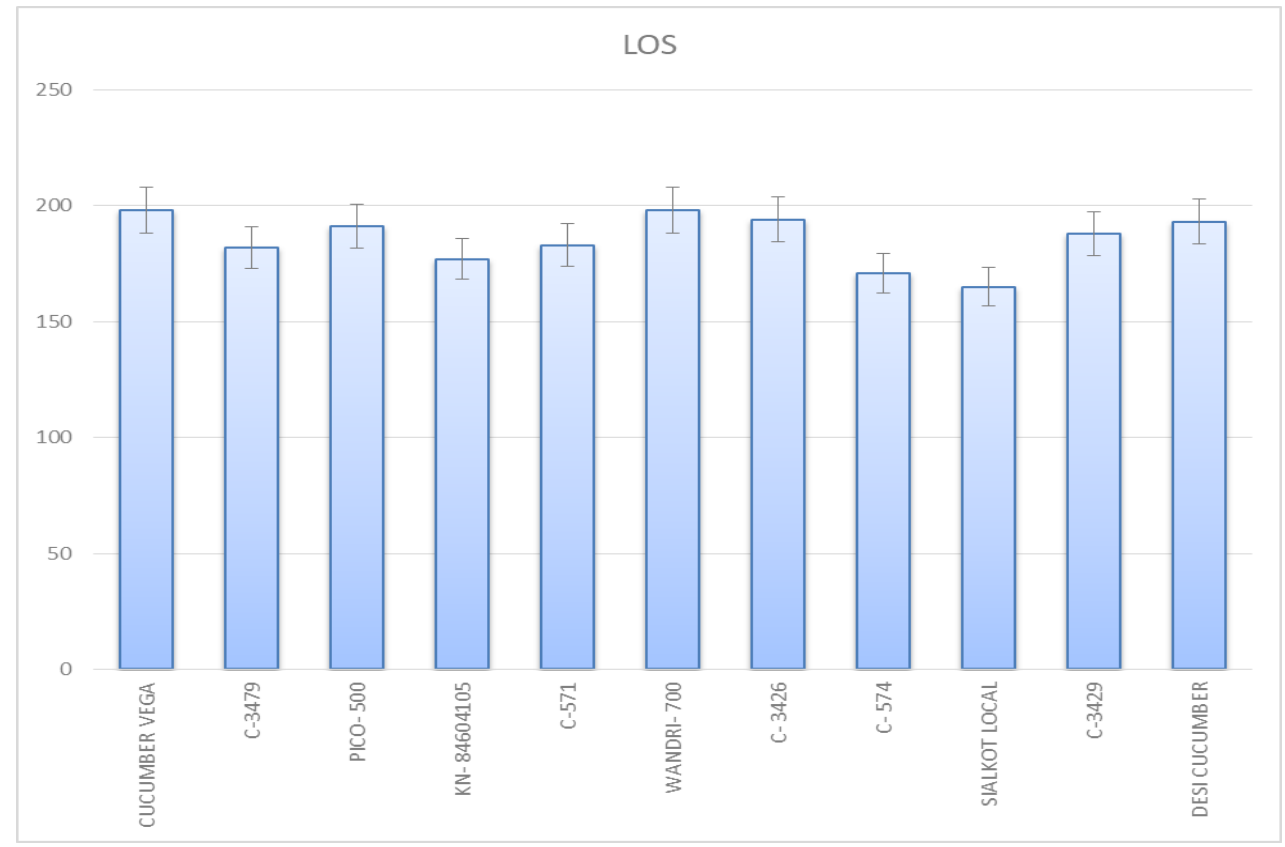

Figure 3 Mean comparison analysis for Length of the Stem.

Figure 3 shows the mean comparison analysis for Length of the Stem. The grouping information graph shows groups of factor level means that are significantly different. This graph is based on the confidence intervals that are displayed in the interval plot. Groups are listed in descending order of their fitted means for the number of treatments. Groups that share a letter, such as treatment T1 and T5, are significantly different; these two treatments' products allowed the most observation to survive. Conversely, groups that do not share a letter have significantly different means. 


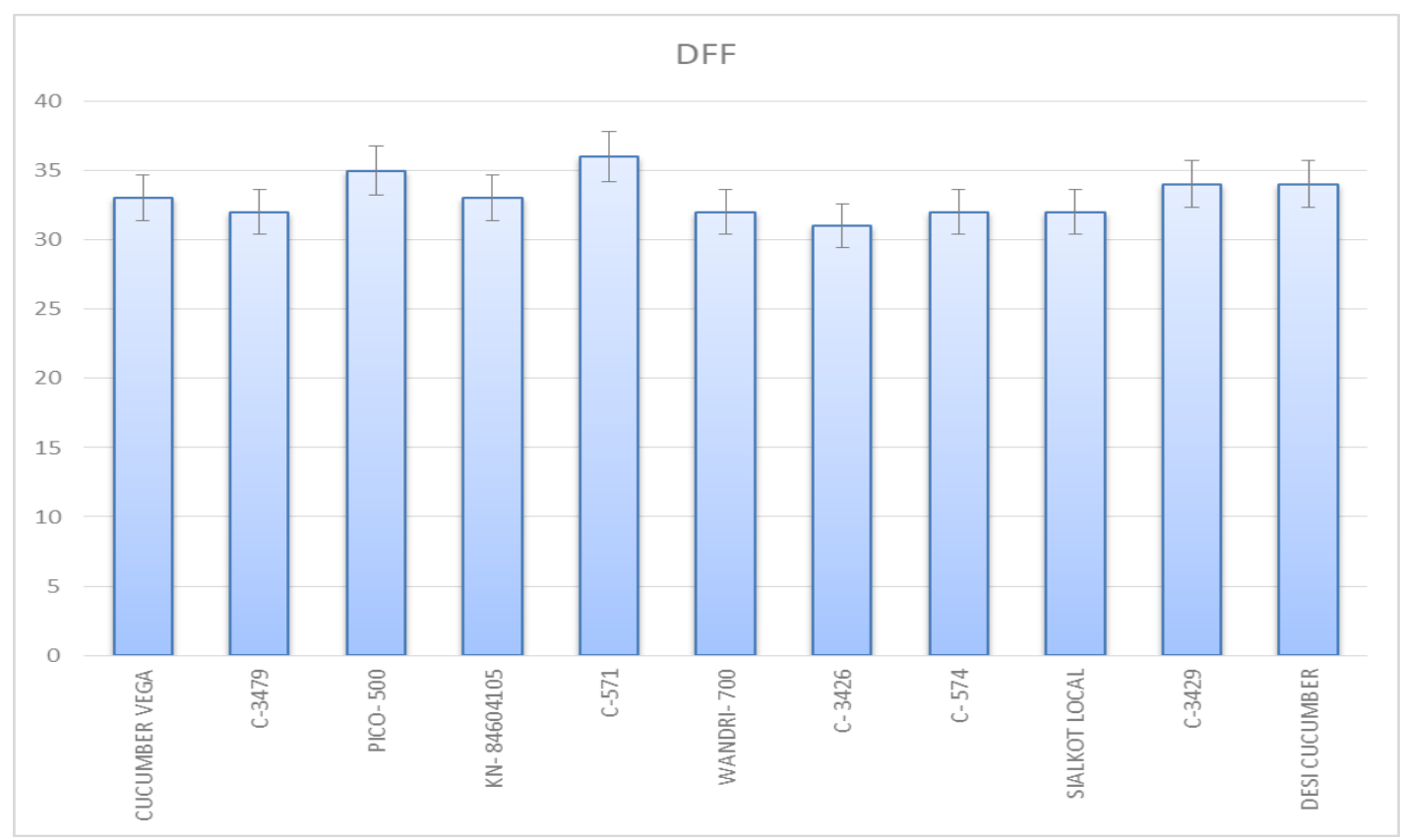

Figure 4 Mean comparison analysis for Days to first flowering.

Figure 4 shows the mean comparison analysis for Days to first flowering. The grouping information graph shows groups of factor level means that are significantly different. This graph is based on the confidence intervals that are displayed in the interval plot. Groups are listed in descending order of their fitted means for the number of treatments. Groups that share a letter, such as treatment T3 and T5, are significantly different; these two treatments' products allowed the most observation to survive. Conversely, groups that do not share a letter have significantly different means.

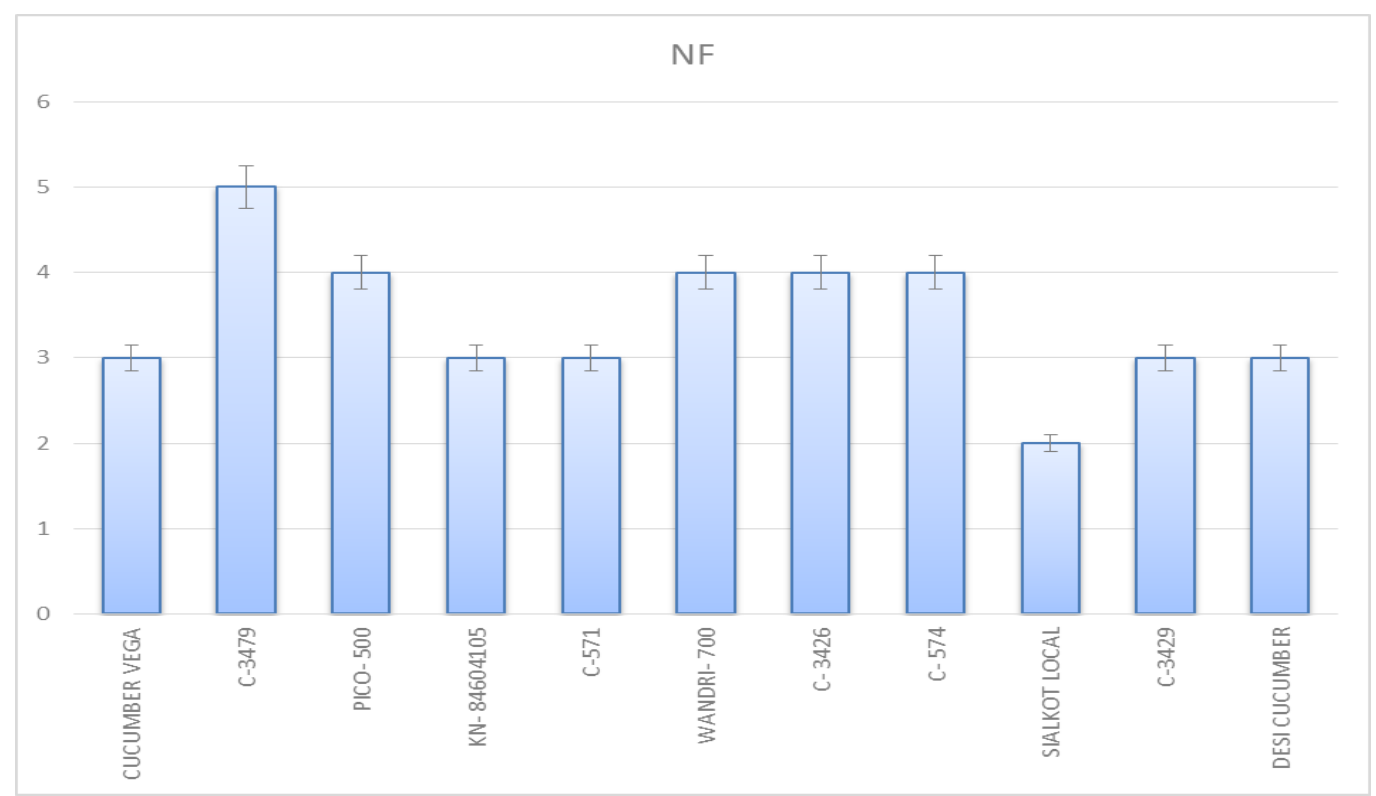

Figure 5 Mean comparison analysis for Number of Fruits

Figure 5 shows the mean comparison analysis for Number of Fruits. The grouping information graph shows groups of factor level means that are significantly different. This graph is based on the confidence intervals that are displayed in the interval plot. Groups are listed in descending order of their fitted means for the number of treatments. Groups that share a letter, such as treatment T2 is significantly different; these two treatments' products allowed the most observation to survive. Conversely, groups that do not share a letter have significantly different means. 


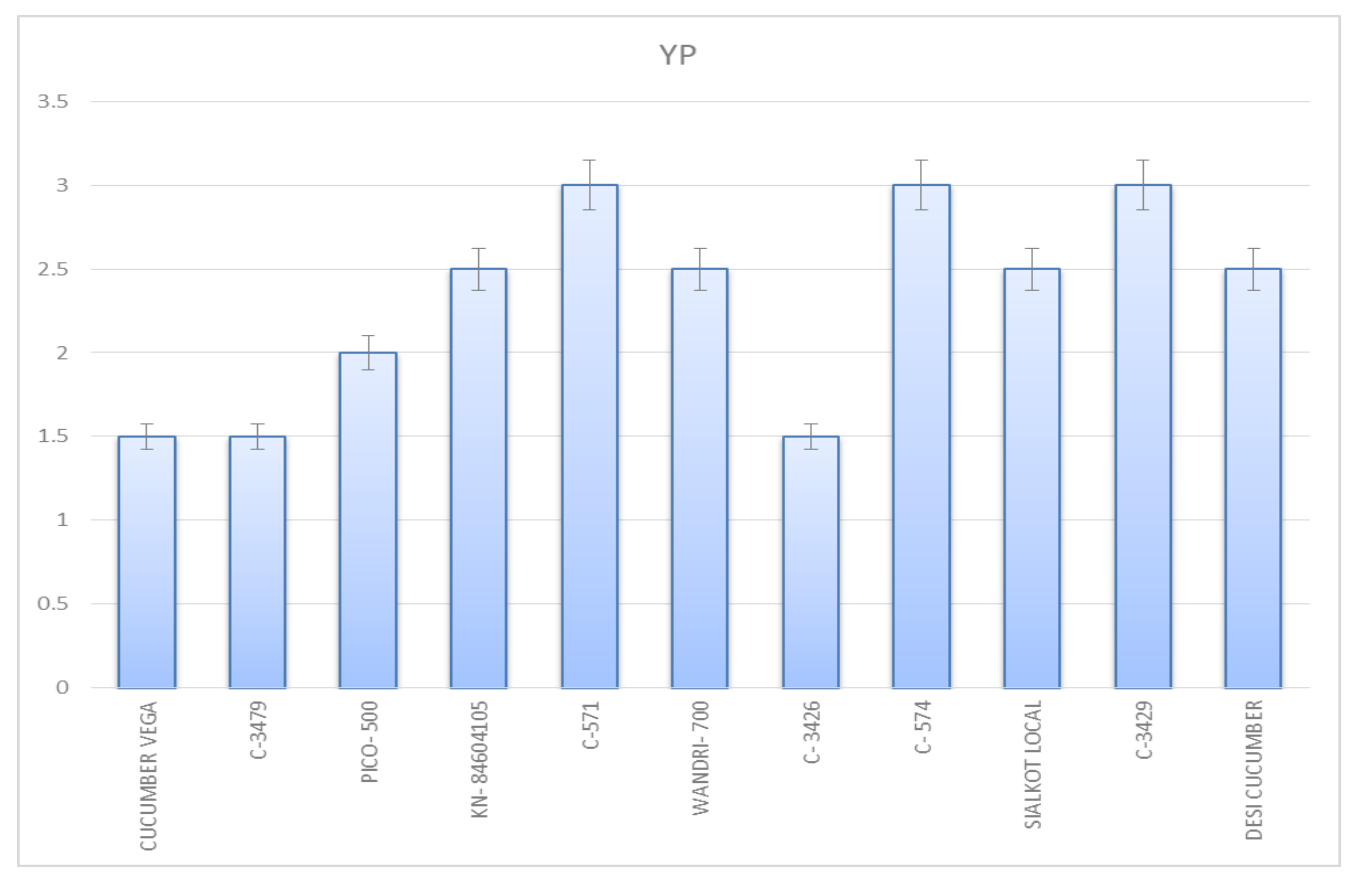

Figure 6 Mean comparison analysis for Yield / Plant

Figure 6 Mean comparison analysis for Yield / Plant. The grouping information graph shows groups of factor level means that are significantly different. This graph is based on the confidence intervals that are displayed in the interval plot. Groups are listed in descending order of their fitted means for the number of treatments. Groups that share a letter, such as treatment T5,8 and T10, are significantly different; these two treatments' products allowed the most observation to survive. Conversely, groups that do not share a letter have significantly different means.

\section{Discussion}

Cucumber is cultivated all around the world and held an important position in cucurbitaceous crops. Seeds of cucumber have cooling, tonic, diuretic and anthelmintic effect. There were total 12 different varieties and central devoutness of the study was to compare all these varieties and to know about the best variety among all. [12] a Russian scientist first time observed the significance in morphological characters are color, size, shape, texture and taste. After comparing means from data it was conducted that in terms of days of germination, the fastest germination rate was observed that three varieties C-571, Cucumber Vega and Desi cucumber respectively followed by C-3429 and remaining varieties showed almost same trend, but the variety which took highest num of days to germinate was C574. All the varieties showed almost similar trend in length of stem and days of flowering. C-3479 possessed highest number of fruits and Sialkot local had lowest number of fruits. Three varieties C-571, 574 and C-3429 exhibited highest yield. The biggest size of leaf was variety WANDRI-700. These results were also similar to [13] that superior the genetic changeability in the existing germplasm, improved was the risks for choosing greater genotypes. Because through the selection of proper germplasm. There are great chances of enhancement in the fruits and yield of the plant. The results of research also matched with [14] In contrast to match Leaf size, length of fruit also sum of fruits. [15] stated that number of 20 different types of cucumber genotypes were collected from changed regions total numbers of branches / plant, altitude of plant, Whole lengths of branches, diameter of shoots and width of leaves played role of significant morphological attributes. Similarly, this research work also provided such varieties in which the leaf size was enhanced and enlarged and varieties having maximum number of fruits were also obtained. The germination rates and other morphological characters were also measured like dry and fresh weight, yield, number of fruits, color of leaves and branches similarly by [16] which justified the evaluation of germination rate and morphological characteristics of four cucumber genotypes were conducted. Experiment was conducted in RCBD with four replications. After $4^{\text {th }}$ and $6^{\text {th }}$ day of planting germination percentage was studied in comparison. This study revealed the germination rates and the fastest germination rate was observed that three varieties C-571, Cucumber Vega and Desi cucumber. In terms of Numb of leaves C-3479, C-571 and Sialkot local beard highest number of leaves. All the varieties similarly as in research done by [17]. Results were also similar as [18] considered variability in twenty-five diverse cucumber genotypes plus observed important differences for traits namely, color of fruit, length of fruit, thickness of fruit, weight of fruit, flesh to seed cavity ratio, marketable numb of fruits / plant, duration of 
harvesting, yield of fruit / plant also length of vine. In the same way our research also described the, maximum and lowermost number of fruits.

\section{Conclusion}

This study revealed the germination rates and the fastest germination rate was observed that three varieties C-571, Cucumber Vega and Desi cucumber. In terms of Numb of leaves C-3479, C-571 and Sialkot local beard highest number of leaves. All the varieties showed almost similar trend in length of stem and days of flowering. C-3479 possessed highest number of fruits and Sialkot local had lowest number of fruits. Three varieties C-571, 574 and C-3429 exhibited highest yield. The biggest size of leaf was variety WANDRI-700In the same way our research also described the, maximum and lowermost number of fruits.

\section{Compliance with ethical standards}

\section{Acknowledgments}

All authors contribute equally and with well manners.

\section{Disclosure of conflict of interest}

No observed conflict of interest among the authors.

\section{References}

[1] Robinson DS. (1990). Food biochemistry and nutritional value. Longman scientific and technical publisher, New York. USA.

[2] Wang YH, T Joobeur RA Dean and JE Staub. (2007). Cucurbits. In: C. Kole. (ed.), Genome mapping and molecular breeding in plants, vegetables, 5, 315-324.

[3] Lawless HT and H Heymann. (1999). Introduction and overview. In: Lawless, H.T., and H. Heymann, editors. Sensory evaluation of food: principles and practices. New York: Kluwer Academic/Plenum Publishers, 1-27.

[4] Sargent SA, SC Stapleton and AJ Fox. (2001). Postharvest Handling Considerations for Greenhouse-Grown Beit Alpha Cucumber. In: Vegetarian Newsletter. University of Florida.

[5] Perl-Treves R. (1999). Male to female conversion along the cucumber shoot approaches to study sex genes and floral development in Cucumis sativus. BIOS Scientific Publishers, 189-286.

[6] Yamasaki S, N Fuji and H Takahashi. (2005). Hormonal regulation of sex expression in plants. Vitamins and Hormones, 72, 79-110.

[7] Miller CH, RL Lower and HP Fleming. (1970). Evaluation of pickles from cucumber plants treated with 2chloroethylphosphonic acid. Hort. Sci, 5, 434-435.

[8] Cantliffe DJ and SC Phatak. (1975). Use of ethephon and chlorflurenol in a once-over pickling cucumber production system. J. Amer. Soc. Hort. Sci, 100, 264-267.

[9] Robinson RW, S Shannon and MD Guardia. (1968). Regulation of sex expression in the cucumber. Bio. Sci. 19, 141-142.

[10] Rudich J, AH Halevy and N Kedar. (1972). The levels of phytohormones in monoecious and gynoecious cucumbers as affected by photoperiod and ethephon. Plant Physiol, 50, 585-590.

[11] Malepszy S and K Niemirowicz-Szczytt. (1991). Sex determination in cucumber (Cucumis sativus) as a model system for molecular biology. Plant Sci, 39-47.

[12] Vavilov NI. (1951). The origin, variation, immunity and breeding of cultivated plants. Chronica Botonica, 13, 1366.

[13] Simmonds NM. (1962). Variability in crop plants, its use and conservation. Botanical Review, 37, 422-465.

[14] Khan Z, AH Shah, R Gul, A Majid, U Khan and H Ahmad. (2015). Morpho-agronomic characterization of cucumber germplasm for yield and yield associated traits, 6, 1-6. 
[15] Golabadi M, P Golkar and E Abdol-Reza. (2012). Assessment of genetic variation in cucumber (Cucumis sativus L.) genotypes. European J. Experimental Biol, 2(5), 1382-1388.

[16] Umeh OA and JC Onovo. (2015). Comparative study of the germination and morphological characteristics of four cucumbers (Cucumis sativus L.) genotypes in Keffi, Nasarawa State, Nigeria. Int. J. Curr. Res. Biosci. Plant Biol, 2(7), 43-46.

[17] Nath TY. (1997). Genetic variability and inter-relationship among horticultural traits in cucumber (Cucumis sativus L.). M.Sc. Thesis, Himachal Pradesh Krishi Viswavidyalaya, Palampur (HP). India.

[18] Sunil V. (2003). Genetic variability and correlation studies in cucumber (Cucumis sativus L.). M.Sc. Thesis, Dr. Y S Parmar University of Horticulture and Forestry, Nauni, Solan.

\section{How to cite this article}

Shehzaib A, Sadique MA, Farooq MU, Shaker MA, Aleem UK and Sana R. (2020). Classification of cucumber germplasm based on agronomic traits under natural climatic conditions. GSC Biological and Pharmaceutical Sciences, 10(2), 148155. 